\title{
Hypoglycemia and hyperglycemia in extremely low-birth-weight infants
}

\author{
Maria Pia De Carolis ${ }^{1 *}$, Serena A Rubortone ${ }^{1}$, Carmen Cocca ${ }^{1}$, Giovanni Pinna ${ }^{1}$, Eloisa Tiberi ${ }^{1}$, Zecca Enrico ${ }^{1}$, \\ Costantino Romagnoli ${ }^{1}$, Silvia Salvi ${ }^{2}$, Sara De Carolis ${ }^{2}$ \\ From XXI Congress of the Italian Society of Neonatology \\ Palermo, Italy. 24-26 September 2015
}

\section{Background}

Glucose metabolism disorders are common in extremely low birth weight (ELBW) infants and are associated with high morbidity and mortality [1-9]. This study was conducted to evaluate the prevalence and risk factors associated with both hypo and hyperglycemia in ELBW infants.

\section{Materials and methods}

All inborn ELBW neonates admitted to our NICU during a 5-year period were eligible for this retrospective analysis. Exclusion criteria were: birth weight $(B W)<400$ grams, major congenital malformations, death during the first 24 hours of life. Hypoglycemia was defined as blood glucose level (BGL) $\leq 45 \mathrm{mg} / \mathrm{dL}$; hyperglycemia as BGL $>240 \mathrm{mg} / \mathrm{dL}$ in a single determination or $>180 \mathrm{mg} / \mathrm{dL}$ in two determinations at 2-hour intervals. Continuous intravenous insulin infusion was started after an ineffective glucose restriction.

\section{Results}

Of 195 ELBW infants, 29 (14.8\%) were excluded and 166 (GA 26.72 .1 weeks, BW 751152 grams) were analyzed and grouped to their BGL. Normoglycemia was observed in 79 neonates (47.6\%) (N-Group); 80 neonates (52.4\%) showed abnormal BGL: 21 (12.7\%) were hypoglycemic (Hypo-Group), 53 (31.9\%) hyperglycemic (Hyper-Group) and 13 (7.8\%) showed both hypoglycemia and hyperglycemia (Hypo\&Hyper-Group). Clinical characteristics of the groups are reported in Table 1. Hypo-Group respect to $\mathrm{N}$-Group showed a higher rate of small for gestational age (SGA) neonates $(p=0.03)$.

\footnotetext{
* Correspondence: mpia.decarolis@rm.unicatt.it

'Division of Neonatology, Department of Obstetrics, Gynecology and Paediatrics, Catholic University of the Sacred Heart, Rome, 00168, Italy Full list of author information is available at the end of the article
}

Hyper-Group in comparison to N-Group showed a tendency toward a lower GA ( $\mathrm{p}=0.05)$, lower $\mathrm{BW}(\mathrm{p}<0.001)$, higher sepsis rate $(\mathrm{p}<0.001)$, higher rate of treatment with inotropic agents $(\mathrm{p}=0.02)$, corticosteroids $(\mathrm{p}=0.006)$ and nonsteroidal antiinflammatory drugs $(\mathrm{p}=0.01)$. Hypo\&Hyper-Group respect to $\mathrm{N}$-Group showed similar GA, lower BW $(\mathrm{p}<0.001)$, higher sepsis rate $(\mathrm{p}<0.01)$, higher rate of inotropic treatment $(\mathrm{p}=0.04)$. Insulin was administered in 35 neonates (66\%) of Hyper-Group and in 8 neonates $(61.5 \%)$ of Hypo\&Hyper-Group. Intraventricular Hemorrhage ( IVH) rate was higher in HyperGroup and Hypo\&Hyper-Group respect to N-Group $(\mathrm{p}=0.002)$ as well as IVH grade3 $(\mathrm{p}=0.001$ and $\mathrm{p}=0.02$, respectively).The rate of both Retinopathy of Prematurity ( ROP) and ROP $\geq$ stage 2 in survived neonates was higher in Hyper-Group respect to N-Group ( $\mathrm{p}=0.008$ and $\mathrm{p}=0.002$, respectively). Mortality was similar among the groups (Table 2).

\section{Conclusions}

Among ELBW infants, hypoglycemia occurs more frequently in SGA neonates, while hyperglycemia alone or a marked variability of BGL (hypo and hyperglycaemia) is more common in sick neonates. High rate of glucose homeostasis disorders highlights the importance of carefully monitoring BGL in order to a prompt management. Continuous glucose monitoring recently used in neonates [10] might be a useful tool for monitoring glucose changes also in ELBW neonates.

\footnotetext{
Authors' details

${ }^{1}$ Division of Neonatology, Department of Obstetrics, Gynecology and Paediatrics, Catholic University of the Sacred Heart, Rome, 00168, Italy. ${ }^{2}$ High Risk Pregnancies Division, Department of Obstetrics, Gynecology and Paediatrics, Catholic University of Sacred Heart, Rome, 00168, Italy.
} 
Table 1 Demographic data and risk factors in the study groups

\begin{tabular}{|c|c|c|c|c|}
\hline & N-Group N=79 & Hypo-Group N=21 & Hyper-Group N=53 & Hypo\&Hyper-Group N=13 \\
\hline $\mathrm{GA}$ (wks), mean $\pm \mathrm{SD}$ & $26.8 \pm 2.0$ & $27.7 \pm 2.4$ & $26.1 \pm 2.1$ & $26.8 \pm 1.8$ \\
\hline $\mathrm{BW}(\mathrm{g})$, mean $\pm S D$ & $808 \pm 136$ & $719 \pm 140$ & $695 \pm 146$ & $692 \pm 140$ \\
\hline Male, n (\%) & $17(21.5)$ & $10(47.6)$ & $26(49.0)$ & $8(61.5)$ \\
\hline SGA, n (\%) & $22(27.8)$ & $11(52.3)$ & $16(30.1)$ & $4(30.7)$ \\
\hline Apgar $^{1}<6, \mathrm{n}(\%)$ & $39(49.3)$ & $9(42.8)$ & $34(64.1)$ & $8(61.5)$ \\
\hline Apgar $^{5}<6, \mathrm{n}(\%)$ & $8(10.1)$ & 0 & $9(16.9)$ & $2(15.3)$ \\
\hline Intubation, n (\%) & $47(59.4)$ & $11(52.3)$ & $37(69.8)$ & $10(76.9)$ \\
\hline Antenatal Steroid, n (\%) & $64(81.0)$ & $17(80.9)$ & $41(77.3)$ & $12(92.3)$ \\
\hline $\mathrm{RDS}, \mathrm{n}(\%)$ & $66(83.5)$ & $19(90.4)$ & $49(92.4)$ & $13(100)$ \\
\hline Sepsis, n (\%) & $16(20.2)$ & $4(19.0)$ & $32(60.3)$ & $7(53.8)$ \\
\hline Inotropic Agents, n (\%) & $26(32.9)$ & $6(28.5)$ & $28(52.8)$ & $8(61.5)$ \\
\hline Xanthines, n (\%) & $70(88.6)$ & $20(95.2)$ & $50(94.3)$ & $13(100)$ \\
\hline Postnatal Steroid, n (\%) & $11(13.9)$ & $3(14.2)$ & $18(33.9)$ & $3(23.0)$ \\
\hline NEC, n (\%) & $6(7.5)$ & $2(9.5)$ & $5(9.4)$ & $4(30.7)$ \\
\hline Medical treatment for PDA, n (\%) & $34(43.0)$ & $8(38.0)$ & $34(64.1)$ & $9(69.2)$ \\
\hline Surgical Procedures, n (\%) & $5(6.3)$ & $3(14.2)$ & $7(13.2)$ & $2(3.7)$ \\
\hline
\end{tabular}

RDS: Respiratory Distress Syndrome; PDA: Patent Ductus Arteriosus; NEC: Necrotizing enterocolitis

Table 2 Complications and outcome in the study groups

\begin{tabular}{ccccc}
\hline & N-Group N=79 & Hypo-Group N=21 & Hyper-Group N=53 & Hypo\&Hyper-Group N=13 \\
\hline IVH, n (\%) & $17(21.5)$ & $7(33.3)$ & $25(47.1)$ & $8(61.5)$ \\
IVH (grade 3, n (\%) & $5(6.3)$ & $1(4.7)$ & $15(28.3)$ & $4(30.7)$ \\
ROP all stages in the survivors, n (\%) & 49 of 61 (80.3) & 10 of 16 (62.5) & 35 of 35 (100) & 7 of $8(87.5)$ \\
ROP > stage 2 in the survivors, n (\%) & 35 of 71 (57.3) & 9 of 16 (56.2) & 35 of 35 (100) & 6 of $8(75)$ \\
Mortality, n (\%) & $18(22.7)$ & $5(23.8)$ & $18(33.9)$ & $6(46.1)$ \\
\hline
\end{tabular}

IVH: IntraventricularHemorrhage; ROP: Retinopathy of Prematurity

\section{Published: 24 September 2015}

\section{References}

1. Lucas A, Morley R, Cole TJ: Adverse neurodevelopmental outcome of moderate neonatal hypoglycaemia. British Med J 1988, 297:1304-1308.

2. Alkalay $A L$, Sarnat $H B$, Flores-Sarnat $L$, Simmons CF: Neurologic aspects of neonatal hypoglycemia. Isr Med Assoc J 2005, 7(3):188-192, Review. Erratum in: Isr Med Assoc J. 2005;7(4):267.

3. Duvanel CB, Fawer CL, Cotting J, Hohlfeld P, Matthieu JM: Long-term effects of neonatal hypoglycemia on brain growth and psychomotor development in small-for-gestational-age preterm infants. J Pediatr 1999, 134:492-498.

4. Kao LS, Morris BH, Lally KP, Stewart CD, Huseby V, Kennedy KA: Hyperglycemia and morbidity and mortality in extremely low birth weight infants. J Perinatol 2006, 26:730-736.

5. Hays SP, Smith EO, Sunehag AL: Hyperglycemia is a risk factor for early death and morbidity in extremely low birth-weight infants. Pediatrics 2006, 118:1811-1818

6. Garg R, Agathe AG, Donohue PK, Lehmann CU: Hyperglycemia and retinopathy of prematurity in very low birth weight infants. J Perinatol 2003, 23:186-194.

7. Au SC, Tang SM, Rong SS, Chen L, Yam JC: Association between hyperglycemia and retinopathy of prematurity: a systemic review and meta-analysis. Sci Rep 2015, 5:9091.

8. Sabzehei MK, Afjeh SA, Shakiba M, Alizadeh P, Shamshiri AR, Esmaili F: Hyperglycemia in VLBW infants; incidence, risk factors and outcome. Arch Iran Med 2014, 17(6):429-434.

9. Auerbach A, Eventov-Friedman S, Arad I, Peleg O, Bdolah-Abram T, Bar$\mathrm{Oz} \mathrm{B}$, Zangen $\mathrm{DH}$ : Long duration of hyperglycemia in the first 96 hours of life is associated with severe intraventricularhemorrhage in preterm infants. J Pediatr 2013, 163(2):388-393.
10. Signal M, Le Compte A, Harris DL, Weston PJ, Harding JE, Chase JG, CHYLD Study Group: Using Stochastic modelling to identify unusual continuous glucose monitor measurements and behaviour, in newborn infants. Biomed Eng Online 2012, 11:45.

doi:10.1186/1824-7288-41-S1-A7

Cite this article as: De Carolis et al:: Hypoglycemia and hyperglycemia in extremely low-birth-weight infants. Italian Journal of Pediatrics 2015 41(Suppl 1):A7.

\section{Submit your next manuscript to BioMed Central and take full advantage of:}

- Convenient online submission

- Thorough peer review

- No space constraints or color figure charges

- Immediate publication on acceptance

- Inclusion in PubMed, CAS, Scopus and Google Scholar

- Research which is freely available for redistribution

Submit your manuscript at www.biomedcentral.com/submit
C Biomed Central 